\title{
ОСОБЕННОСТИ ЯЗЫКОВОЙ ИНТЕРФЕРЕНЦИИ ВО ФРАНЦУЗСКОМ ЯЗЫКЕ МАРОККАНСКИХ БИЛИНГВОВ
}

\author{
Е. В. Кашкина
}

Воронежский государственный университет

\author{
FEATURES OF LANGUAGE INTERFERENCE \\ IN THE FRENCH LANGUAGE OF MOROCCAN BILINGUALS
}

\author{
E. V. Kashkina \\ Voronezh State University
}

\begin{abstract}
Аннотация: в статье идет речь о различных типах языковой интерференции, которые наблюдаются во франиузском языке в ситуации марокканского франко-арабского билингвизма. Цель исследования: наполнить термин «интерференция» конкретным языковым материалом; осуществить классификацию примеров фактического материала; сформулировать общие и частные выводы для углубления и совершенствования процесса знакомства с особенностями интерференций во франиузском языке марокканцев. Для достижения поставленной цели использовался сравнительно-сопоставительньй метод и метод контекстуального анализа. Одним из направлений исследования в рассматриваемой области является поиск путей объяснения механизмов фонетических, лексических и морфосинтаксических ошибок, которые совершают во франиузском языке марокканские арабофоны. Материалом исследования послужил роман современной писательнищы билингва, ведущей повествование от лица пятнадцатилетней марокканки. Интерференщия, проявляющаяся на всех уровнях во франиузском языке марокканцев, носит, прежде всего, количественный характер. Лексическая интерференция обязана, прежде всего, буквальному переводу слов, кальке, которые являются марокканскими реалиями. Синтаксическая интерференция, присутствующая в исследуемом произведении, более глубинная по своей сути, так как меняет структурные особенности франиузского языка. Франиузское предложение принимает несвойственные ему формы, гибридные конструкции, что отражается на качестве перевода. Фонетическая интерференция во франиузском языке марокканиев имеет некоторые особенности, но в иелом не мешает коммуникации и переводу. Особенности марокканского варианта французского языка важно учитывать российским переводчикам. Краткое знакомство с примерами языковой интерференщии, их классификаџия настраивают на продолжение исследования региональных особенностей франиузского языка.
\end{abstract}

Ключевые слова: лингвистическая интерференция, билингвизм, перевод, варианты языков, фонетическая и грамматическая интерференции.

Abstract: the article deals with the various types of linguistic interference that are observed in the French language in the situation of Moroccan Franco-Arabic bilingualism. The purpose of the research is to fill the term "interference" with specific linguistic material; to classify examples of factual material; to formulate general and particular conclusions for deepening and improving the process of acquaintance with the features of interference in the French language of Moroccans. To achieve this goal, the comparative-contrastive method and the method of contextual analysis were used. One of the areas of research in the area under consideration is the search for ways to explain the mechanisms of phonetic, lexical and morphosyntactic errors that Moroccan Arabophones make in French. The research material was the novel of a modern bilingual writer, narrating on behalf of a fifteenyear-old Moroccan woman. The interference that manifests itself at all levels in the French language of Moroccans is primarily quantitative. Lexical interference happens primarily due to the literal translation of words, modelling words after foreign patterns, which are Moroccan realities. The syntactic interference present in the studied work is deeper in its essence, since it changes the structural features of the French language. The French sentence takes

(C) Кашкина Е. В., 2020 
on unusual forms, hybrid constructions, which affects the quality of the translation. Phonetic interference in the French language of Moroccans has some peculiarities, but, in general, does not interfere with communication and translation. It is important for Russian translators to take into account the peculiarities of the Moroccan version of the French language. A brief acquaintance with examples of linguistic interference, their classification is set up to continue the study of regional features of the French language.

Key words: linguistic interference, bilingualism, translation, language variants, phonetic and grammatical interference.

\section{Введение}

Знакомство с особенностями французского языка, функционирующего за пределами метрополии, - это насущная проблема, так как французский язык в различном статусе присутствует приблизительно в пятидесяти странах мира и является официальным в 29 государствах, в основном африканских, где он неизбежно испытывает влияние местного языка или языков, диалектов, культур. Актуальность темы также обусловлена изменениями, которые происходят во французском языке под влиянием языка мигрантов на стандартный язык метрополии. Следовательно, качество работы переводчика зависит, в том числе, от его осведомленности о существовании языковой специфики и региональных особенностях французского языка. Наличие акцента, различные отклонения грамматического и синтаксического свойства препятствуют успешной коммуникации, скорости и точности перевода. Этот факт признается на самом высоком уровне. На сайте ООН в разделе о работе лингвистических служб речь идет о навыках понимания региональных вариантов языков, так как для перевода «дополнительную проблему создает тот факт, что многие делегаты выступают не на родном языке. Устные переводчики должны понимать все возможные акценты и переводить независимо от скорости или стиля выступления, при этом по возможности стараясь сохранить все тонкости текста оригинала» [1]. Понимание французской речи затруднено наличием разных языковых девиаций, проявляющихся в большей или меньшей степени под влиянием родных языков у билингвов ${ }^{1}$. Явление билингвизма и диглоссии сопровождает присутствие французского языка в арабоязычных странах Магриба. Влияние первого языка на второй с наибольшей очевидностью проявляется в интерференции, которая характеризуется ошибками, т. е. контактно обусловленными отклонениями по определению У. Вайнрайха [2].

Предметом наших наблюдений стали различные виды интерференции во французском языке марокканцев. Среди стран Магриба Марокко представляет собой самую мозаичную и сложную языковую картину, где французский язык, не имеющий официаль-

${ }^{1}$ Об этом студентам Воронежского госуниверситета рассказала атташе посольства РФ в Рабате выпускница МГИМО Д. Веселовская во время прохождения переводческой практики в Марокко в феврале-марте 2019 г. ного статуса, выполняет практически функции второго государственного языка после арабского. Исторически сложилось так, что сто лет назад французский язык оказался в регионе с самобытной культурой и богатыми традициями, основанными на арабо-берберском фундаменте. Французский язык обогащается арабизмами, региональными реалиями, воспринимает грамматический строй и фонологическую специфику языка иной структуры, т. е. подвергается интерференции. Однако, по мнению Г. М. Вишневской, «в научной среде нет единства в трактовке основных понятий теории интерференции, нет единой методологии и методики изучения явлений интерференции» [3, с. 35]. Таким образом, анализ и объяснение интерферентных явлений, которые в некоторой степени являются основой движения стандартного языка к своему иному состоянию - региональному варианту или даже новому языку, не теряет свою актуальность.

Для исследования использовался материал перевода на русский язык романа «Туда-сюда» Фаизы Гэн [4], повествование от лица 15-летней марокканки и оригинал Faîza Guène «Kiffe kiffe demain» [5]. А также отрывок из этого произведения, который представлен в учебнике французского языка Le français.ru, B 1, Е. Б. Александровской, содержащий около двух десятков примеров языковой интерференции [6, с. 131].

Нестандартный язык повествования Ф. Гэн письменный текст с характеристиками устной речи - создает иллюзию, что рассказчик говорит с читателем, используя арго, заимствования, верлан и ксенизмы. Его язык насыщен грамматическими и фонологическими особенностями, свойственными французскому языку марокканцев. Таким образом, исследуемое произведение, интересное само по себе, предлагает обильный материал для изучения языковой интерференции, анализа ее причин и для ознакомления с ней студентов, поскольку «практика доказывает, что совмещение обычных заданий и намеренно «нашпигованных» в них явлений интерференции действует сильнее на подсознание и откладывается в долговременную память, нежели отдельное изучение проблемы, которое с зачетом вылетает у студента из головы» [7, с. 173-175]. Немаловажным считаем также то, что произведение существует как в оригинальной версии, так и в переводе на русский язык, что позволяет находить примеры интерференций, давать объяснения 
ее возникновения, знакомиться со стратегиями и способами преодоления интерференции при сопоставлении текстов оригинала и перевода и собственных вариантов перевода. Язык используемого произведения - это живой язык французской молодежи, то, что называют «le français contemporain des cités», т. e. современный французский язык пригородов [8], и говорить на нем сегодня - это своеобразная мода. Он впитал в себя особенности речи марокканских арабофонов.

В настоящей статье мы ставим следующие цели и задачи: осуществить классификацию примеров фактического материала; наполнить термин «интерференция» конкретным языковым материалом; сформулировать общие и частные выводы для углубления и совершенствования процесса знакомства с интерференций во французском языке марокканцев. Для достижения поставленной цели использовался сравнительно-сопоставительный метод и метод контекстуального анализа. Сравнение в нашем случае выступает как средство, а не как цель.

\section{Результаты исследования}

Из явления, которое долгое время считалось языковой ошибкой или искажением иностранного языка под влиянием родного [9, с. 313-318], интерференция в настоящее время является предметом активного исследовательского интереса таких лингвистических направлений, как межкультурная коммуникация, структурная лингвистика, теория языковых контактов, социолингвистика, лингвострановедение и т. д. Вопросы интерференции освещают в своих работах отечественные и зарубежные ученые: Е. М. Верещагин, Г. М. Вишневская, В. В. Климов, Л. Н. Ковылина, В. Н. Комиссаров, Н. А. Любимова, Р. К. Миньяр-Белоручев, Н. Б. Мечковская, В. Ю. Розенцвейг, Г. Д. Томахин, Е. Бужаровска, У. Вайнрайх, Э. Хауген и др. $\mathrm{C}$ конца прошлого столетия интерференцию изучают отечественные теоретики перевода И. С. Алексеева, В. В. Алимов, и общепринятым считается мнение, что «перевод - это область, где интерференция неизбежна. Она результат того, что структура исходного языка накладывается неосознанно на целевой язык» [10]. И. С. Алексеева считает, что «само наличие интерференции зависит от профессиональной компетенции переводчика, и переводчик может уменьшить ее с помощью специальных поправок, осознавая меру расхождений между двумя языками, с которыми он работает» $[11$, с. 170]. У. Вайнрайх определяет интерференцию как «случаи отклонения от норм каждого языка, происходящие в речи билингвов в результате их знакомства более чем с одним языком» $[12$, с. 7]. То есть при интерференции, в отличие от переключения языковых кодов, происходит изменение одного языка под влиянием другого. Интерфе- ренция может охватывать все уровни языка: фонетический, грамматический, лексический, семантический, культурный и другие виды интерференции.

Повествование Ф. Гэн демонстрирует примеры фонетической, морфологической, синтаксической и лексической интерференции, тесно связанной с культурной. Сразу оговоримся, что приведенные примеры не являются перечислением всех возможных случаев, а представляют собой анализ некоторых типичных примеров.

Фонетическая интерференциия возникает как адаптация, часто бессознательная, звука к фонетической системе языка, когда говорят на другом языке. Фонетическая и фонологическая интерференция - это первое, с чем сталкивается переводчик, коммуницируя в среде с нестандартным французским языком. Например, явление назализации, свойственное французскому языку, отсутствует в арабском языке. В примере показано, как неразличение носовых звуков

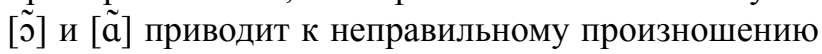
фамилии и дальше к конфликту.

Cet enfoiré de M. Schihont, il a cru que Maman se moquait de lui parce qu'avec son accent elle prononce son nom Schihant [5, p. 131]. - Этот козел, месье Шиан, думает, что мама над ним издевается, потому что из-за своего акиента она произносит Ссшан $[4$, c. 11$]$.

Причина конфликта в том, что женщина не различает носовых звуков и произносит фамилию директора как крайне фамильярное слово «chiant», дающее негативную характеристику предметам и лицам.

В поисках эффекта реальности, живого разговорного языка автор старается сохранить в своем повествовании характеристики устной речи, т. е. язык, который демонстрирует «экономию усилий» и, следовательно, отдает приоритет лексической экономии. Например, в использовании гласного звука [ә] немое, который может опускаться в определенных позициях. Выпадение [ә] становится все более частым и необоснованным, когда автор использует язык, создающий эффект уличной речи жителей французских пригородов. Его опущение оправдано тем, что в фонологической системе арабского языка такой звук отсутствует. Таким образом звук [е] в личном местоимении “је" - я, полностью исчезает:

...j'crois bien que je vais arrêter de faire la voix off à la télé (...) j'veux dire personne nous demande des autographes dans la rue à nous (...) J'vais créer une association: Les Voix off anonymes, parce que personne lit mon nom au générique de fin de reportages. J'en ai marre, j'suis à bout... M'en fous [5, p. 71]. - Bom ия думаю, зачем мне заниматься закадровым озвучиванием (...) никто не просит у нас автограф на улице (...). Я создам собственную ассоциацию анонимных 
закадровых голосов, потому что никто не прочтет наших фамилий в титрах в коние репортажа. Мне надоело, я больше не могу... Мне плевать [4, с. 115].

В последнем предложении мы видим уже исчезновение и самого местоимения-подлежащего, что может свидетельствовать о наложении не только фонетической, но уже морфосинтаксической системы арабского языка, где распространены глагольные предложения, которые начинаются с глагола, и отсутствует подлежащее.

Фонологическая интерференция присутствует также в ошибочном употреблении гласных [е] и [i], $[y]$ и $[\mathrm{u}]$, потому что говорящий на арабском языке их не различает, так как фонологическая система арабского языка имеет только три гласные [i], [u], [a].

Si vous prounez cridit sur cridit, on est toujours pas sourtis de la berge !! - Если будищ брать крэдит на крэдит, мы никогда не рассчитаемся!!

L'institoutrice elle doumande à Toto: «combien ça fait douze bouteille de vin, à dou euros la pièce?» [4, p. 39]. - Учитэлница спрашивает у Тото: «Сколько стоит двэнадцуать бутилок вина по два евро бутил$\kappa a ? »[5$, c. 63].

Персонаж книги, таким образом, путает звуки [у] и [u], затем [e] и [i]. То, что автор назвала «блидарским акцентом» - «accent de blédard» (от арабского bled родина, деревня, захолустье), в действительности является фонетической интерференцией. В целом, фонетическая и фонологическая интерференция создает незначительные помехи при понимании представленного текста, как и в целом французского языка марокканцев. Однако отклонения фонологического характера влияют на скорость перевода, а также иногда могут искажать смысл высказывания.

Elle voulait que sa fille soit la plus belle à l'occasion de l'écoule neuf, la jdida... hamdoullah [5, p. 81]. - Она хотела, чтобы ее дочь была самая красивая [4, c. 130].

В этом примере Ясмина, мать героини, путает две фонемы: [o] и [u]: «écoule/école»- школа. Слово écoule в потоке речи может восприниматься как форма глагола «écouler» (вытекать). Это предложение может вызвать сложность при переводе и для понимания в потоке речи. Интерференцию объясняет смыслоразличительное проявление просодии. В результате появляются ошибки, в том числе морфологического характера, в то время как они происходят от ошибочного распознавания фонем.

Синтаксическая интерференция или морфосинтаксическая интерференция имеет место там, где в язык билингва вводятся единицы и сочетания частей речи, грамматических категорий и функциональных морфем, происходящих из другого языка [13, p. 92]. Синтаксическая интерференция в большей степени создает трудности при понимании и переводе из-за того, что чуждая конструкция, включаясь во французское предложение, затуманивает смысл, а переводчик может потерять нить переговоров. Характеристики интерференции на морфосинтаксическом или синтагматическом уровне проявляются в нашем материале в опущении подлежащего, что при знании такой особенности не вызывает при переводе особых затруднений.

...y a pas de service après vente $[6$, p. 131] - ... mym не предъявишь претензию к качеству товара [4, с. 8].

$Y$ a pas très longtemps, Maman a commencé a travailler [4, p. 6]. - Совсем недавно мама пошла рабomamb $[4$, c. 10].

Самые многочисленные примеры грамматической интерференции в произведении - это опущение первой отрицательной частицы пе из двух (ne... pas), присутствующих во французском языке, которая стоит перед глаголом, и опущение пе также в выделительном обороте. В отрывке из учебника насчитывается десять таких примеров и практически без исключений во всем тексте романа.

Quand je pense qu'il y a des filles qui font pas exprès de tomber enceintes du premier coup... [5, p. 131]-Kaк же девчонки залетают с первого раза? [4, с. 8].

Disons que je correspondais pas tout à fait au désir du client [6, p. 131]. - А я, скажем так, не вполне отвечала требованиям клиента [4, с. 8].

...c'est comme le sida, ça existe qu'en Afrique [6, p. 131] - ...это что-то вроде спида, бывает только в Африке [4, с. 10].

В родном языке героини повествования используется одна отрицательная частица, в отличие от французского, где их две. Также это особенность разговорного французского языка. При переводе как раз эти примеры вызывают наибольшие затруднения. Из-за того, что вторая часть отрицания стоит после глагола, переводить фразу на русский язык приходится как утвердительное предложение с соответствующей интонацией. В итоге это приводит к скомканности перевода, потере темпа и требует от переводчика последующей самокорректировки.

Несколько примеров касаются нормы употребления неопределенного артикля, которого в арабском языке нет. Во французском языке есть неопределенный артикль des множественного числа, но перед группой прилагательное + существительное он имеет тенденцию заменяться предлогом de.

Aujourd'hui, elle m'a sorti de son tiroir du bas une collection d'images bizarres, des grosses taches qui ressemblaient à du vomi séché [6, p. 131]. - Сегодня она вытащцла из своего нижнего ящика коллекцию причудливых изображений, большие пятна, похожие на выссохиую рвоту [4, с. 7].

В данном примере согласно грамматическому правилу должно быть: «de grosses taches». С другой 
стороны, в произведении есть еще примеры такого типа, которые вполне соответствуют грамматическому правилу, и поэтому невозможно однозначно сказать, что вызывает употребление ошибочной формы. Этот вопрос может обеспечить тему для будущих исследований. Следует обратить внимание на противопоставление автором стандартного французского языка с его четкой фонетикой и структурированной грамматикой - языку улицы, будь то во Франции или в Марокко.

Синтаксическая интерференция в книге Ф. Гэн имеет также некоторые черты, которые относятся к разговорной речи марокканцев на французском языке. В частности, это синтаксическая избыточность, когда в начале предложения, стоит номинальная группа либо ударное местоимение, которое дублируется личным местоимением и может состоять из двух одинаковых графем.

Elle, elle aimait jouer et voulait faire son métier. Lorsqu'elle a eu dix-huit ans, avec sa troupe elle a même pu participer à des pièces dans plusieurs villes de France [5, p. 1]. - А она любила играть и любила свою работу. В восемнадияать лет ей даже удалось съездить со своей труппой по городам Франичи [6, р. 139].

Есть также примеры разрыва синтаксических связей подлежащего и сказуемого, повтора подлежащего-существительного личным приглагольным местоимением.

Alors un jour, le barbu, il a dî se rendre compte que ça servai à rien d'essayer avec ma mère et il s'est cassé [6, p. 131]. - Так что в один прекрасный день он понял, что с матерью уже ничего не получится, и слинял [4, c. 8$]$.

A lui, ça va lui coûter une vraie fortune-tout l'argent de sa retraite d'ouvrier chez Renault [6, p. 131]. - Eмy это обойдется в цуелое состояние, придется цуеликом выложить пенсию, которую он получает от завода Рено [4, с. 8].

В речи марокканца на французском языке это примеры избыточного выражения субъекта, что объясняется структурой родного языка. Для арабского предложения свойственно явление усиления, т. е. в синтаксической конструкции есть усиливаемое слово и усиливающее. Для этого могут использоваться повторы одного и того же слова или синонима. Поскольку говорящий марокканец не ставит целью выделить подлежащее и не изменил интонационный контур, то эта избыточность иллюстрирует явление интерференции. При переводе такая конструкция в целом не вызывает затруднений, но иногда переведенное предложение принимает несвойственную русскому языку конструкцию или просторечное звучание.

Другой случай, который функционирует как выделительный оборот во французском языке, в речи арабофона - это изменение порядка слов в предложе- нии, когда глагол предшествует другим частям предложения и предмету в конце.

Quand arrive enfin mon tour. - Когда наконец наступает моя очередь.

Данный пример в момент перевода может вызвать некоторые затруднения в связи с тем, что вопросительное наречие quand, стоящее в начале независимого предложения, предполагает вопросительную интонацию с повышением тона или измененную структуру фразы. Как мы уже упоминали, глагольные предложения в арабском языке начинаются с глагола, за которым следуют подлежащее и дополнение. Этот порядок является нормой для арабского языка. Такая структура легко переходит в речь марокканца, говорящего по-французски, этот пример также отражение синтаксических особенностей арабского языка [14, с. 56-65].

Лексическая интерференция в большинстве случаев вызывается межъязыковыми связями, это вмешательство лексики одной языковой системы в другую, как следствие, может наблюдаться семантическая модификация французских элементов. В целом, это, вероятно, самые частые случаи интерференции в речи, благодаря неограниченному количеству лексики и, как пишет У. Вайнрайх, «ввиду легкости распространения лексических единиц (по сравнению с фонологическими и грамматическими правилами)», также он считает, что «основополагающим условием для лексической интерференции и является ощущение лексического дефицита» [12, с. 211]. Лексический уровень интерференции является особенностью стиля Ф. Гэн в книге «Туда-сюда». Само название «Kiffe kiffe demain» настраивает переводчика на поиски подходящего эквивалента. В данном случае присутствует еще и игра слов, поскольку интерференция часто сопровождается возникновением двойного смысла, основанного на паронимической аттракции [15, с. 55-64]. На слух слово kif-kif, происходящее из североафриканского региона, которое активно используется в речи французов, означает «то же самое, точь-в-точь» [16], т. е. kif-kif demain - то же самое завтра. В написании это уже другая часть речи - глагол kiffer, образованный из арабской основы [kiff], который означает «любить, получать удовольствие», на молодежном сленге - «кайфовать» [17].

В целом именно лексика сделала уникальным данное повествование, в частности, благодаря использованию большого количества экзотизмов, жаргонных слов разных типов, арабизмов, ксенизмов и т. д. Лексика дает социокультурную характеристику персонажам и реалиям современного французского общества, как и марокканского.

Et puis à la rentrée, Olivia elle est toujours en kiffe mais Trav, lui, pour flamber devant les potes du lycée, il la calcule plus parce qu'il a honte d'elle [5, p. 75]. - A потом начинается учебный год. Оливия по-прежнему 
влюблена, а Трав, чтобы казаться крутым перед лицейскими дружбанами, на нее не смотрит, он ее стылытея [4, с. 123].

В данном примере интересно словосочетание elle est toujours en kiffe, в которое автор включает глагол, как показано выше, образованный от арабской основы kiff - любить. Во французском языке существует глагол aimer, как и конструкция être amoureux (amoureuse) - быть влюбленным. Для арабофона глагол kiffer имеет более конкретное значение - любить, по сравнению с французским, где aimer - это также нравиться, дорожить.

Mme Burlaud, elle est vieille, elle est moche et elle sent le Parapoux [6, p. 131]. - Мадам Бюрло старая и некрасивая, от нее пахнет средством от блох [4, с. 7].

В данном примере студенты поправили переводчика, так как parapoux переводится как средство от вией. Здесь наблюдается переводческая интерференция, так как для русскоязычного переводчика, видимо, некомфортно осознание наличия вшей у французских персонажей.

Ma mère dit que si mon père nous a abandonnées, c'est parce que c'était écrit. Chez nous on appelle ça le mektoub [5, p. 9]. - Мама говорит, что отец нас бросил, потому что так было предначертано судьбой. По-нашему - «мектуб» [4, с. 14].

Тут автор употребляет арабский термин, переводчик использует кальку. В арабском языке существительное мектуб мужского рода, означает предначертание, по-французски - la prédestination, слово, которое почти вышло из употребления. Mektoub имеет более широкое значение в арабском языке - предначертание судьбы.

Pour qu'on voie mieux mes yeux, Maman me les a entourés de khôl [5, p. 81]. - Чтобы глаза были ярче, мама обвела их черной краской [6, с. 131].

Слово khôl означает черный порошок из минералов сурьмы, которым при помощи палочки подводят глаза.

Арабская лексика этих примеров, обозначающая местные реалии, интегрирована в речь и уже присутствует во французских словарях. Множество религиозных выражений из арабского языка находят свое полное объяснение только на нем. Французский язык, функционирующий преимущественно в христианском обществе, безусловно, имеет эквиваленты семам: maktoub (судьба), hallouf (свинья), Allah (Бог), но не может исчерпывающе передать их исламскую коннотацию. Многие слова сопровождаются эквивалентами, калькой, что гарантирует для переводчика релевантность; автор делает повторы с использованием арабских слов, сохраняя арабскую орфографию.

En plus, y aura toute la cité au mariage d'Aziz et si Maman fait ça, c'est la honte. La "hchouma"! [5, p. 56]-
К томуже на свадьбе у Азиза будет весь квартал, $и$ если мама так скажет, это будет позор, «хиума» $[4$, c. 91$]$.

Мы согласны с мнением А. Н. Черкасовой, что «одно из основных отличий марокканского варианта французского языка от французского языка Франции базируется на особенностях лексического состава арабских заимствований» [18]. Во французский язык Марокко проникло заметное количество лексических заимствований арабского и берберского происхождения, которые сначала постепенно интерферируют, а потом подчиняются грамматическим нормам французского языка, занимают место в его словарном составе. С точки зрения лингвокультурологии наиболее интересными представляются случаи интерференции, когда арабские слова получают грамматическое оформление, свойственное французскому языку. Наблюдение за данными примерами лексической интерференции свидетельствует, что эта лексика уже узус, а не отклонение от нормы.

Приведенные в примерах лексические единицы, утвердившиеся во французском языке и оформленные по французским правилам, придают ему своеобразие и новую окраску и неразрывно связаны с культурной интерференцией, которая, по мнению А. В. Щепиловой, вызвана не самой системой языка, а культурой, которую данный язык отражает. Вызвать интерференцию могут сходные в разных культурах реалии, явления, нормы поведения [19, с. 78]. Это преимущественно лексика, обозначающая этнографические, религиозные, бытовые реалии, характерные для региона.

Quand elle était jeune, une de ses voisines s'était fait marabouter au souk, à peine un mois avant son mariage [5, p. 26]. - Когда она была ещуе молодой, на одну ее подружку на базаре навели порчу за месяи до свадьбыл $[4$, c. 44$]$.

Вера в колдовство, использование амулетов для различных ритуалов составляют важную часть марокканской культуры. Глагол marabouter означает наложить заклятье. Он образован от арабского слова marabout (марабут - отшельник, местный святой). В стандартном французском языке в этом значении используется другое выражение. В нашем случае интерференция наблюдается как культурный перенос и сдвиг значения (святой и наведение порчи). Слово souk означает «базар в североафриканских странах», таким образом, во французском языке в результате интерференции имеет место сужение значения слова.

Pendant le ramadant, elle lutte encore plus parce qu'à l'heure de la coupure, vers 17h30, elle est encore au travail [6, p. 131]. - Во время Рамадана ей еще труднее, потому что в половине шестого вечера надо кончать работу и приступать кеде, а она не может $[4$, c. 11$]$. 
Речь идет о прерывании поста (голодания) вечером, с заходом солнца, а не просто об окончании работы, слово рамадан означает мусульманский пост. Культурные традиции марокканцев неочевидны для незнакомых с ними переводчиков французского языка, из-за чего они могут допускать смысловую расплывчатость при переводе.

Je me souviens des vieilles tatouées qui venaient $s$ 'assoir à coté de Maman pendant les mariages, baptêmes ou circoncisions [5, p. 10]. - На всех свадьбах, рождениях и обрезаниях рядом с мамой пристраивались какие-то татуированные старухи [4, с. 15].

Студентам, которые побывали в Марокко, не составило труда осмысленно перевести этот отрывок. Речь идет о татуировках на щеках, лбу и подбородке, которые делают исключительно женщины из берберских племен Марокко. Это фоновая информация культурного характера, интегрированная во французскую фразу, скажет переводчику, а он - читателю: героиня берберского происхождения, непокорность и вольнодумие имеют корни в традиционном свободолюбии этого автохтонного народа, который сохранил и после арабского завоевания свой язык и архаичную культуру. Опираясь на свой опыт перевода интерферентных явлений, студенты предложили, что было бы целесообразно сделать приложение с переводческими комментариями допускаемых ошибок, лексики и культурных вмешательств в изучаемом произведении. Такое приложение может стать продолжением работы в данном направлении.

\section{Выводы}

Как показывает наше исследование, расхождения в структурах французского языка (норма и узус арабофонов) многообразны и относятся к базовым для изучающих французский язык. Интерференция, проявляющаяся на всех уровнях во французском языке марокканцев, разнообразна и носит, прежде всего, количественный характер. Лексическая интерференция, тесно связанная с заимствованиями, включается в структуру языка, не нарушая ее, а обогащает французский язык марокканцев, который становится более ярким и самобытным. Лексическая интерференция обязана, прежде всего, буквальному переводу слов, кальке, которые являются марокканскими реалиями. Синтаксическая интерференция, присутствующая в исследуемом произведении, менее выражена количественно, однако более глубинная по своей сути, так как именно морфосинтаксическое вмешательство меняет структурные особенности французского языка. Французское предложение принимает несвойственные ему формы, гибридные конструкции, что также отражается на качестве перевода. Фонетическая интерференция во французском языке марокканцев хотя и имеет некоторые особен- ности, но в целом не мешает коммуникации и переводу, как это происходит, например, с французским языком южнее экватора.

Изучение различных видов языковой интерференции, количественных и качественных сдвигов во французском языке арабофонов следует продолжать, привлекая интернет-ресурсы, используя возможности при прохождении переводческой практики и т. д., подкрепляя имеющийся материал статистическими данными. Собранные примеры позволят выявлять степень отклонения от стандартного французского языка до уровня, когда можно будет говорить о появлении марокканского варианта французского языка, и в самом крайнем случае - о появлении нового языка, как это произошло с французским языком в Канаде.

Практическое применение знания видов языковой интерференции, распознание и классификация ее примеров, анализ отклонений во французском языке арабофонов дает лингвистическое обоснование закономерностям перевода, важное для специалистов, работающих в Марокко и в странах Магриба. Профессиональная компетентность переводчика заключается в способности осознания интерферентных явлений для их нивелирования.

\section{ЛИТЕРАТУРА}

1. URL: https://www.un.org/ru/observances/russianlanguage-day/services

2. Weinreich $U$. Languages in Contact: Findings an problems. New York : Cambridge University Press, 1953. $60 \mathrm{p}$.

3. Вишневская Г. М. Билингвизм и его аспекты : учеб. пособие / Иван. гос. ун-т. Иваново, 1997. 98 с.

4. Фаиза Гэн. Туда-Сюда : Роман. СПб. : Лимбус Пресс, 2006. 160 c.

5. Faiza Guène. Kiffe-kiffe demain. Paris : Hachette jeunesse, 2006. $189 \mathrm{p}$.

6. Александровская Е. Б., Лосева Н. В., Читахова Л. Л. Учебник французского языка Le français.ru B2-С1. Книга 1. М., 2009. 254 с.

7. Желнова Е. С. Перевод и межъязыковая интерференция // Филология и лингвистика в современном обществе : материалы II Междунар. науч. конф. (г. Москва, февраль 2014 г.). М. : Буки-Веди, 2014. С. 173-175. URL: https: // moluch.ru/conf/phil/archive/107/5036/ ]

8. Jean-Pierre Goudaillier - Comment tu tchatches! Dictionnaire du français contemporain des cités. Paris, 1997. $190 \mathrm{p}$.

9. Щерба Л. В. К вопросу о двуязычии // Щерба Л. В. Языковая система и речевая деятельность. Л., 1974. $428 \mathrm{c}$.

10. Gellerstam Martin. Modern Swedish Text Corpora // Directions in Corpus Linguistics. Berlin, 1992. Pp. 112113.

11. Алексеева И. С. Введение в переводоведение : учеб. пособие. СПб. : Академия, 2004. 352 с. 
12. Вайнрайх У. Языковые контакты. Состояние и проблемы исследования. Благовещенск, 2000. 264 с.

13. Mackey $W$. Bilinguisme et contact des langues. Paris : ed. Klincksieck, 1976. 534 p.

14. Кашкина E. В. Синтаксическая интерференция в простом предложении (на примере французского языка в Марокко) // Научное обозрение : гуманитарные исследования. М. : Наука образования, 2017. 75 с.

15. Кузнецова И. Н. О лексическом смешении, или интерференции // Вестник Московского университета. 2005. № 4. C. 55-64.

16. URL: https:// dic.academic.ru/dic.nsf/fre rus/40608/

17. URL: https:// www.larousse.fr/dictionnaires/ francais/kiffer/10909977

18. Черкасова А. П. Арабская лексика французского языка стран Магриба // Известия Саратовского университета. Нов. сер. Сер. Филология. Журналистика. 2013. Т. 13, вып. 2. С. 13-16.

19. Щепилова A. В. Теория и методика обучения французскому языку как второму иностранному. М. : Владос, 2005. 245 с.

\section{REFERENCES}

1. Available at: https://www.un.org/ru/observances/ russian-language-day/services

2. Weinreich U. Languages in Contact: Findings an problems / U.Weinreich. New York: Cambridge University Press, 1953. 60 p.

3. Vishnevskaya G. M. Bilingvizm i ego aspekty: ucheb. posobie / Ivan. gos. un-t. Ivanovo, 1997. 98 p.

4. Faiza Gehn. Tuda-Syuda: Roman. SPb.: OOO «Izdatel'stvo Limbus Press», 2006. 160 p.

5. Faiza Guène. Kiffe-kiffe demain. Paris, Hachette jeunesse, 2006. 189 p.

6. Aleksandrovskaya E. B., Loseva N. V., CHitakhova L. L. Uchebnik frantsuzskogo yazyka Le français.ru B2-C1, kniga 1. 2009. 254 p.

Воронежский государственный университет

Кашкина Е. В., дочент кафедры франиузской филологии

E-mail: uelha@bk.ru

Поступила в редакцию 15 апреля 2020 г.

Принята к публикации 25 сентября 2020 2.

\section{Для цитирования:}

Кашкина Е. В. Особенности языковой интерференции во французском языке марокканских билингвов // Вестник Воронежского государственного университета. Серия: Лингвистика и межкультурная коммуникация. 2020. № 4. C. 107-114. DOI: https://doi.org/10.17308/ lic. $2020.4 / 3086$
7. Zhelnova E. S. Perevod i mezh'yazykovaya interferentsiya. In: Filologiya i lingvistika v sovremennom obshhestve: materialy II Mezhdunar. nauch. konf. (g. Moskva, fevral' 2014 g.). M.: Buki-Vedi, 2014. Pp. 173-175. Available at: https://moluch.ru/conf/phil/archive/107/5036/ ]

8. Jean-Pierre Goudaillier - Comment tu tchatches! Dictionnaire du français contemporain des cités, Paris, 1997. $190 \mathrm{p}$.

9. Sherba L. V. K voprosu o dvuyazychii. In : SHHerba L. V. YAzykovaya sistema i rechevaya deyatel'nost'. L., 1974. $428 \mathrm{p}$.

10. Gellerstam Martin. Modern Swedish Text Corpora. In: Directions in Corpus Linguistics. Berlin, 1992. Pp. 112-113.

11. Alekseeva I. S. Vvedenie v perevodovedenie: uchebnoe posobie. SPb.: Akademiya, 2004. 352 p.

12. Vajnrajkh U. YAzykovye kontakty. Sostoyanie i problemy issledovaniya. Blagoveshhensk, 2000. 264 p.

13. Mackey W. Bilinguisme et contact des langues. Paris: ed. Klincksieck, 1976. 534 p.

14. Kashkina E. V. Sintaksicheskaya interferentsiya v prostom predlozhenii (na primere frantsuzskogo yazyka $\mathrm{v}$ Marokko). In: Nauchnoe obozrenie: gumanitarnye issledovaniya. Izdatel'skij dom «Nauka obrazovaniya». Moskva, 2017. 75 p.

15. Kuznetsova I. N. O leksicheskom smeshenii, ili interferentsii. In: Vestnik Moskovskogo universiteta. 2005. No. 4. Pp. 55-64.

16. Available at: https://dic.academic.ru/dic.nsf/fre rus/40608/

17. Available at: https://www.larousse.fr/dictionnaires/ francais/kiffer/10909977

18. Cherkasova A. P. Arabskaya leksika frantsuzskogo yazyka stran Magriba. In: Izvestiya Saratovskogo universiteta. Nov. ser. Ser. Ilologiya. Zhurnalistika. 2013. T. 13, vyp. 2. Pp. 13-16.

19. Shepilova A. V. Teoriya i metodika obucheniya frantsuzskomu yazyku kak vtoromu inostrannomu. M.: tsentr Vlados, 2005. 245 p.

Voronezh State University

Kashkina E. V., Associate Professor of the French Philology Department

E-mail:uelha@bk.ru

Received: 15 April 2020

Accepted: 25 September 2020

\section{For citation:}

Kashkina E. $V$. Features of language interference in the French language of Moroccan bilinguals. Proceedings of Voronezh State University. Series: Linguistics and Intercultural Communication. 2020. No. 4. Pp. 107-114. DOI: https://doi.org/10.17308/lic.2020.4/3086 